\title{
Metal ion levels in large-diameter total hip and resurfacing hip arthroplasty-Preliminary results of a prospective five year study after two years of follow-up
}

\author{
W. Maurer-Ertl, J. Friesenbichler", P. Sadoghi, M. Pechmann, M. Trennheuser and A. Leithner
}

\begin{abstract}
Background: Metal-on-metal hip resurfacing is an alternative to metal-on-metal total hip arthroplasty, especially for young and physically active patients. However, wear which might be detected by increased serum ion levels is a matter of concern.

Methods: The aims of this preliminary study were to determine the raise of metal ion levels at 2-years follow-up in a prospective setting and to evaluate differences between patients with either resurfacing or total hip arthroplasty. Furthermore we investigated if the inclination of the acetabular component and the arc of cover would influence these findings. Therefore, 36 patients were followed prospectively.

Results: The results showed increments for $\mathrm{Co}$ and $\mathrm{Cr}$ in both implant groups. Patients treated with large-diameter total hip arthroplasty showed fourfold and threefold, respectively, higher levels for Co and $\mathrm{Cr}$ compared to the resurfacing group (Co: $p<0,001$ and $\mathrm{Cr}: \mathrm{p}=0,005$ ). Nevertheless, we observed no significant correlation between serum ion levels, inclination and arc of cover.

Discussion: In order to clarify the biologic effects of ion dissemination and to identify risks concerning long-term toxicity of metals, the exposure should be monitored carefully. Therefore, long-term studies have to be done to determine adverse effects of $\mathrm{Co}$ and $\mathrm{Cr}$ following metal-on-metal hip replacement.
\end{abstract}

Keywords: Hip resurfacing, Total hip arthroplasty, Prosthetic wear, Cobalt, Chromium

\section{Background}

Metal-on-metal hip resurfacing or total hip arthroplasty (THA) became an accepted and widespread procedure for joint replacement due to the favourable wear pattern, especially in young and physically active patients [1-5]. Therefore, several manufacturers introduced different hip resurfacing systems and large-diameter hip arthroplasty devices.

Nevertheless, the number of revisions for failed hip arthroplasties using metal-on-metal articulation increased, especially following hip resurfacing. The main drawback of metal articulation is the production of metal wear debris leading to elevated concentrations of metal

\footnotetext{
* Correspondence: joerg.friesenbichler@medunigraz.at

Department of Orthopaedic Surgery, Medical University of Graz, Graz, Austria
}

ions (Cobalt (Co), Chromium (Cr) and Molybdenum (Mo)) within the hip joint, the periarticular soft tissues and systemically [3,6-20]. Furthermore, there are several other factors leading to a variability in the serum levels of metal ions such as different implant size, incorrect adjustment of the components (inclination, anteversion, arc of cover), and differences in manufacture and metallurgy as well as metal corrosion [4-8,16,17,19,21,22].

Up to now there have been many studies investigating the characteristics of metal ions in the human body after hip arthroplasty with metal-on-metal bearings [1-18,2128]. Increased concentrations have been found to be associated with hypersensitivity, local soft tissue reactions (pseudotumors), metallosis, and several other adverse effects [1-3,5-7,11,18-20,23,25]. Nevertheless, it remains unclear whether adverse reactions are dose- 
dependent and whether they are mediated by an immune response or if they are a toxicological effect [6].

Herein, we present the preliminary results of serial serum metal ion determination after 2 years in a prospective series over a five year period in patients who had undergone metal-on-metal hip resurfacing or largediameter total hip arthroplasty. The primary aim of this preliminary study was to determine the raise of metal ion levels at 2-years follow-up in a prospective setting. The secondary aim was to evaluate differences between patients with either resurfacing or total hip arthroplasty and if the inclination of the acetabular component and the arc of cover would influence these findings.

The first study hypothesis was, that metal ion levels would increase after 2-years of follow-up in both groups. The second hypothesis was that inclination of the acetabular component and the arc of cover would positively influence elevated metal ion levels.

\section{Methods}

A series of 36 patients who underwent metal-on-metal THA or hip resurfacing were followed prospectively over a 5-year period. For resurfacing hip arthroplasty a porous coated anatomical system was used (Articular Surface Replacement System-ASR ${ }^{\mathrm{TM}}$, DePuy, Warsaw, IN). For metal-on-metal THA a porous coated anatomical system with a large diameter femoral head (both $\mathrm{ASR}^{\mathrm{TM}} \mathrm{XL}$ Head, DePuy) was combined with a standard femoral shaft (Corail $^{\circledR}$ or Future ${ }^{\circledR}$, DePuy). All prostheses were manufactured from Co-Cr-Mo alloy according to ISO 5832-4.

The surgeries were performed by six senior orthopaedic surgeons, using a modified antero-lateral (THA) or a posterior approach (resurfacing arthroplasty). Press fit fixation of the acetabular components and femoral stems was performed in all patients and the femoral resurfacing component was cemented.

Five men and 3 women were included in the resurfacing group ( $\mathrm{n}=8$ resurfacings). These patients were chosen for this procedure due to their physically activeness and their young age at time of operation (mean: 47years, range, 33-57 years). The THA group included 28 patients (15 men and 13 women) with a mean age at operation of 52-years (range, 40-61 years). During the study period 4 patients of the THA group required replacement of the contralateral hip ( $\mathrm{n}=32$ THAs) using the same metal-on-metal device. Patient demographics are reported in Table 1.

Determination of metal ion concentrations was performed preoperatively, 6 weeks, 3 and 6 months postoperatively, and annually thereafter.

\section{Metal ion sampling}

Blood was taken from 36 patients treated with metal-onmetal hip resurfacing or metal-on-metal total hip
Table 1 Patient demographics, gender distribution and component details

\begin{tabular}{lll}
\hline Demographics & ASR Resurfacing & ASR XL Head \\
\hline Number of patients & 8 & 28 \\
Number of hips & 8 & 32 \\
M:F (\% female) & $5: 3(37,5)$ & $15: 13(46,4)$ \\
Mean age in yrs (range) & $47(33$ to 57$)$ & $52(40$ to 61$)$ \\
Mean body mass index in $\mathrm{kg} / \mathrm{m}^{2}$ & $24,5(21,3$ to 27,7$)$ & $27,8(21,6$ to 37,6$)$ \\
Mean acetabular size in $\mathrm{mm}$ & $55(50$ to 58$)$ & $52(46$ to 58$)$ \\
Mean femoral size in $\mathrm{mm}$ & $49(45$ to 51$)$ & $46(41$ to 51$)$ \\
\hline
\end{tabular}

All values are mean and shown with their range.

arthroplasty using stainless-steel needles attached to $9 \mathrm{~mL}$ no additive plastic vacuum tubes $\left(\right.$ VACUETTE $^{\circledR}$ ). All needles and tubes were used from the same batch. None of the patients had a history of renal impairment.

All specimens were centrifuged for 10 minutes at $4300 \mathrm{rpm}$ within 2 hours and stored at $4^{\circ} \mathrm{C}$ until analysis. The concentrations of $\mathrm{Co}, \mathrm{Cr}$ and Mo were determined using electrothermal graphite furnace atomic absorption spectrometry (ET ASS) in the same laboratory (Medical and Chemical Laboratory Diagnostic Lorenz \& Petek $\mathrm{GmbH}$ ). This method of analysis has been chosen due to high sensitivity and reduced matrix effects (Zeeman Effect). A second tube was stored at the department at $-20^{\circ} \mathrm{C}$ due to the availability in case of further studies. Furthermore, the metal ion measurements can be repeated at any time if necessary.

For analysis, $300 \mu \mathrm{l}$ of each serum sample were diluted with $50 \mu \mathrm{l}$ Modifier und $550 \mu \mathrm{l}$ Aqua dest. (Rotipuran). Control samples as well as a standard samples were diluted in the same way. Fifty $\mu \mathrm{l}$ Modifier and $850 \mu \mathrm{l}$ Aqua dest. (Rotipuran) were used as blank values of the reagents. The ET ASS has been repeated twice for each sample and the levels of metal ions in the serum were recorded in concentrations expressed as $\mu \mathrm{g} / \mathrm{dl}$.

The sample to be examined was evaporated in an atomization apparatus and transformed into atomic condition. With graphite furnace atomic absorption spectrometry, solved samples were charged in a graphite tube with a micro pipette and liberated from the solvent and other concomitant agents by stepwise heating before being atomized. This produced a signal with an area proportional to the element of interest. The concentration of the dilution could be calculated by using the dosed volume of the sample.

\section{Radiological analysis}

Weight-bearing, anteroposterior digital radiographs from the pelvis and the operated hip were made one week, 3 months, 1 year and 2 years postoperatively. The inclination angle of the acetabular component was measured from the intersection of two lines on the anteroposterior 
radiograph of the pelvis, one line across the edges of the component and the other joining both tear trop signs (Figure 1a). According to the study of De Haan et al. [22] the inclination was considered steep if the angle was higher than $55^{\circ}$. Furthermore, the implants' arc of cover was calculated (Figure 1b) [22]. If the arc of cover was less than $10 \mathrm{~mm}$, elevated metal ion levels in serum were expected because the smaller the arc of cover the greater the tendency to rim-loading [6]. All measurements were performed using the Synedra view program, personal version 1.0.12.3 (Synedra information technologies $\mathrm{GmbH}$, Innsbruck, Austria). We correlated metal ion levels with inclination and the arc of cover.

\section{Statistical analysis}

Spearmen's rank correlation coefficient was calculated separated for each implant group to show if there was a correlation between the concentrations of $\mathrm{Co}, \mathrm{Cr}$ and Mo in the serum, the inclination of the acetabular component and the arc of cover. A Mann-Whitney-U test was performed to determine differences in median serum metal ion concentrations at the follow-up checks. This non-parametric test was chosen due to the asymmetric distribution of metal ion levels. A $p$-value of $<0,05$ was considered to be statistical significant. For statistic analysis the PASW Statistics 16.0 program (SPSS Inc., Chicago, IL) was used.

The study was approved by the Ethics Committee of the Medical University of Graz (EK17-265 ex 05/06) and written informed consent was obtained from all patients.

\section{Results}

The median results for cobalt and chromium in the serum of patients with the $\mathrm{ASR}^{\mathrm{TM}}$ resurfacing device

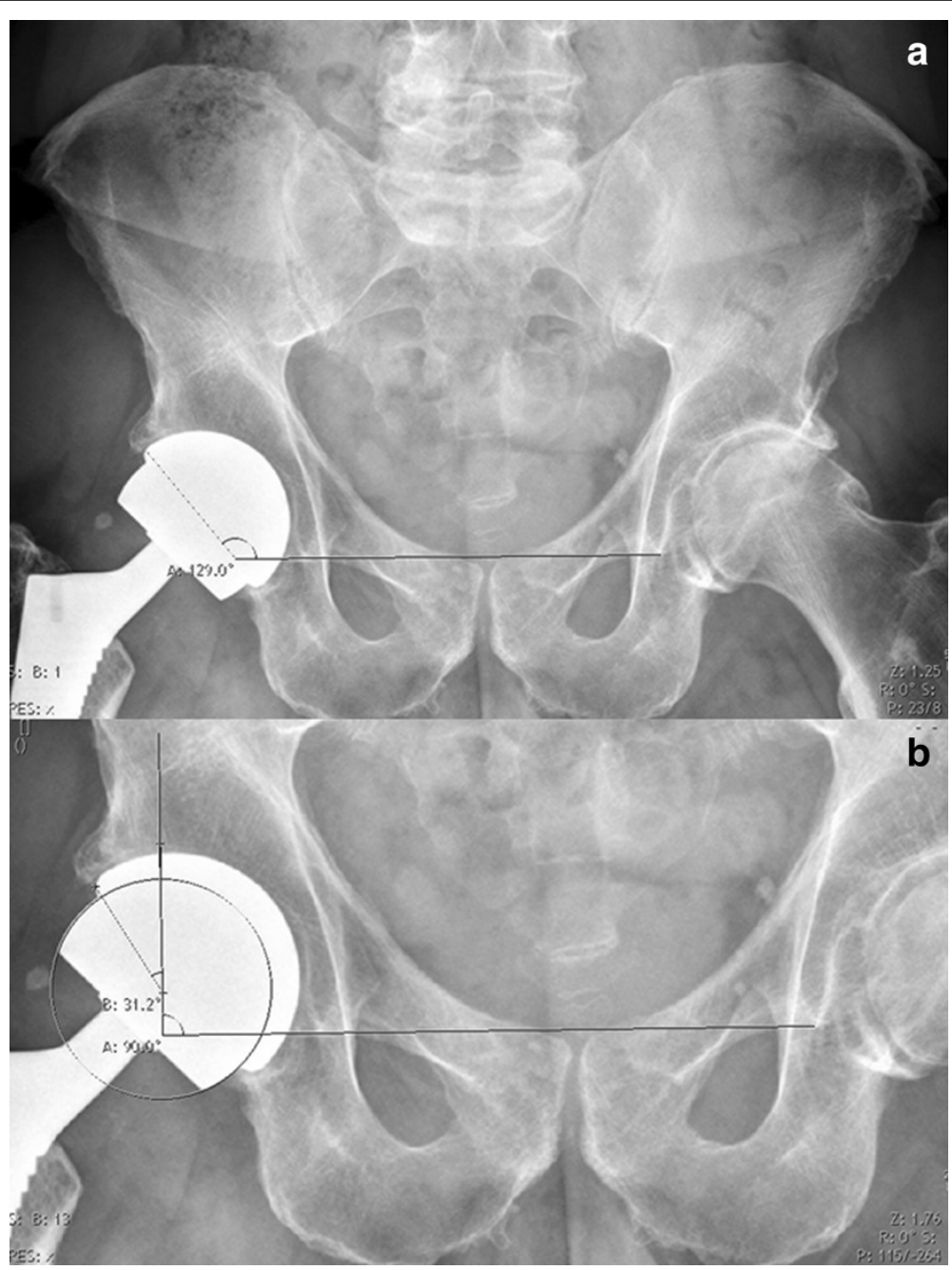

Figure 1 a\&b. Plain radiographs of the pelvis of a 46-year-old female patient with an $\mathrm{ASR}^{\mathrm{TM}} \mathrm{XL}$ Head device two years following implantation. a) Measuring cup inclination. b) Measurements to determine the arc of cover according to the method described by De Haan et al. in 2008 . 


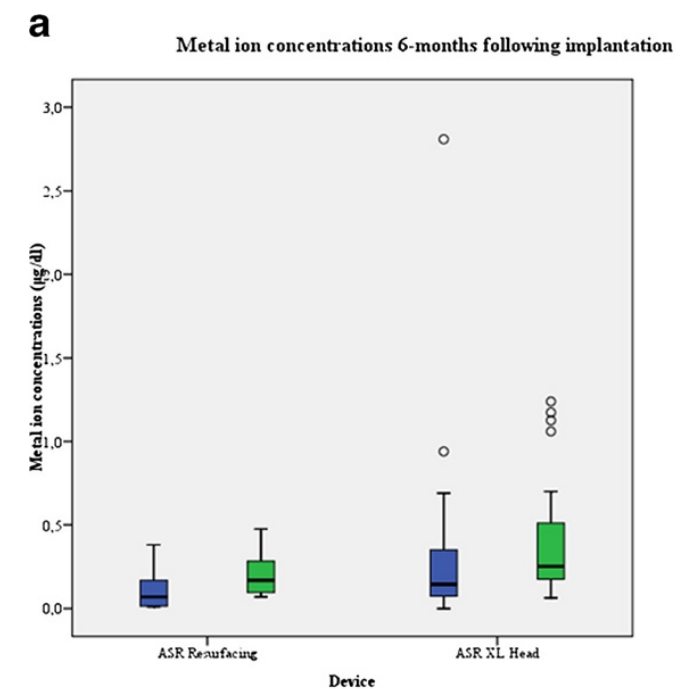

b Metal ion concentrations l-year following implantation

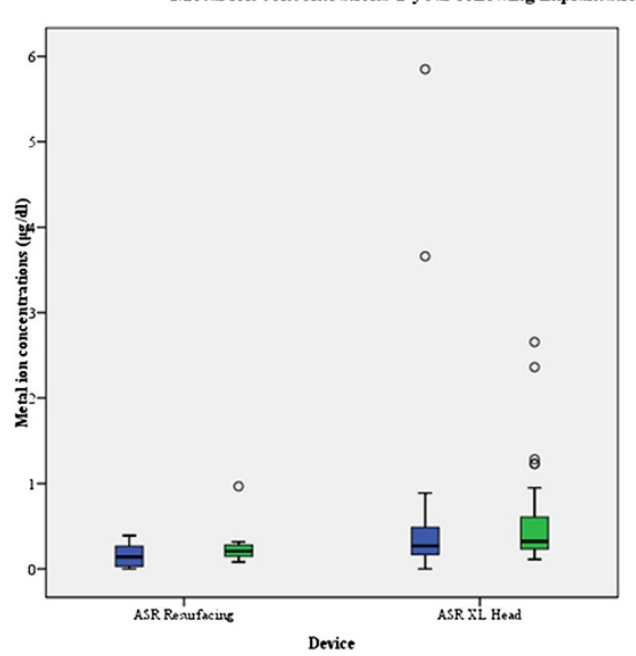

$$
\text { C }
$$
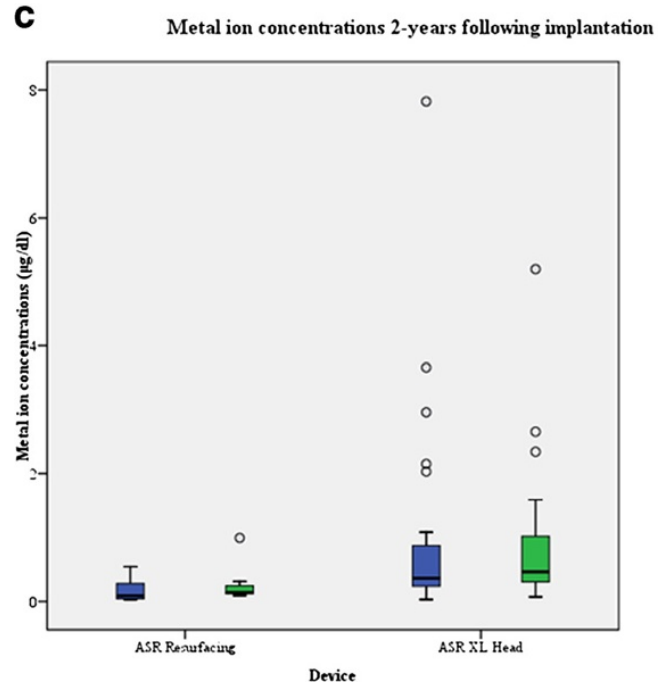

Figure 2 a-c. Box plot of metal ion concentrations devided by resurfacing and THA group, a) 6-months, b) one year and c) two yeras following implantation.

were $0,09 \mu \mathrm{g} / \mathrm{dl}$ (range, $0,03-0,54 \mu \mathrm{g} / \mathrm{dl}$ ) and $0,141 \mu \mathrm{g} / \mathrm{dl}$ (range, 0,092-0,990 $\mu \mathrm{g} / \mathrm{dl}$ ) 2 years following implantation (Figure 2a-c; Table 2). In comparison to that, patients with the $\mathrm{ASR}^{\mathrm{TM}} \mathrm{XL}$ Head device revealed median concentrations of $0,36 \mu \mathrm{g} / \mathrm{dl}$ (range, 0,03-7,82 $\mu \mathrm{g} / \mathrm{dl}$ ) and $0,458 \mu \mathrm{g} / \mathrm{dl}$ (range, 0,071-5,198 $\mu \mathrm{g} / \mathrm{dl}$ ) for $\mathrm{Co}$ and $\mathrm{Cr}$ (Figure 2a-c; Table 2). The values for $\mathrm{Co}$ and $\mathrm{Cr}$ were fourfold and threefold, respectively, higher in the THA group compared to the resurfacing group. These differences for $\mathrm{Co}(\mathrm{p}<0,001)$ and $\mathrm{Cr}(\mathrm{p}=0,005)$ were statistically significant (Table 2 ).

Determining the correlation between the concentration of $\mathrm{Co}$ and $\mathrm{Cr}$ in the resurfacing group revealed a statistically not significant result (Spearmen: 0,695; $p=0,056)$, while this correlation was significant in the THA group (Spearmen: 0,805; $<<0,001$; Table 3).

Two years following implantation, the mean inclination of the acetabular component was $41^{\circ}$ (range, $35^{\circ}-61^{\circ}$ ) in the resurfacing group and $45,5^{\circ}$ (range, $28^{\circ}-68^{\circ}$ ) in the THA group (Table 2). Nevertheless, differences in inclination were statistically not significant $(\mathrm{p}=0,351)$. Consequently, there were not significant differences in the arc of cover ( $p=0,281$; Table 2). Calculations revealed no significant correlations between the concentrations of metal ions in the serum, the inclination of the acetabular component, as well as the arc of cover in both groups (Table 3). Probably, the current study failed to show a correlation between metal ion levels, inclination and arc of cover due to the small number of patients included.

\section{Discussion}

The primary aim of this preliminary study was to determine the raise of metal ion levels at 2-years follow-up in a prospective setting. The secondary aim was to evaluate differences between patients with either resurfacing or total hip arthroplasty and if the inclination of the acetabular component and the arc of cover would influence these findings.

The first study hypothesis was, that metal ion levels would increase after 2-years of follow-up in both groups. The second hypothesis was that inclination of the acetabular component and the arc of cover would positively influence elevated metal ion levels.

Our findings showed an increment of $\mathrm{Co}$ and $\mathrm{Cr}$ concentrations in the serum of patients following metal-onmetal hip resurfacing as well as THA within the first 2years following implantation with significant differences in $\mathrm{Co}$ and $\mathrm{Cr}$ concentrations between the resurfacing and large-diameter THA group (Co: $\mathrm{p}<0,011, \mathrm{Cr}$ : 


\begin{tabular}{|c|c|c|c|}
\hline Serum metal ion levels & ASR Resurfacing & ASR XL Head & Significance \\
\hline \multicolumn{4}{|l|}{ Median Co $(\mu g / d l)$} \\
\hline preoperative & $0,02(0$ to 0,03$)$ & $0,00(0$ to 0,54$)$ & 0,504 \\
\hline 6 weeks & $0,06(0,01$ to 0,19$)$ & $0,07(0$ to 0,30$)$ & 0,780 \\
\hline 3 months & $0,04(0$ to 0,33$)$ & $0,10(0$ to 0,66$)$ & 0,143 \\
\hline 6 months & $0,07(0,01$ to 0,38$)$ & $0,14(0,00$ to 2,81$)$ & 0,134 \\
\hline 1 year & $0,14(0$ to 0,39$)$ & $0,27(0$ to 5,85$)$ & 0,068 \\
\hline 2 years & $0,09(0,03$ to 0,54$)$ & $0,36(0,03$ to 7,82$)$ & 0,011 \\
\hline \multicolumn{4}{|l|}{ Median $\mathrm{Cr}(\mu \mathrm{g} / \mathrm{dl})$} \\
\hline preoperative & $0,020(0,010$ to 0,030$)$ & $0,026(0,007$ to 0,753$)$ & 0,293 \\
\hline 6 weeks & $0,100(0,060$ to 0,140$)$ & $0,101(0,050$ to 0,443$)$ & 0,802 \\
\hline 3 months & $0,137(0,097$ to 0,398$)$ & $0,176(0,059$ to 0,724$)$ & 0,404 \\
\hline 6 months & $0,170(0,070$ to 0,475$)$ & $0,253(0,064$ to 1,240$)$ & 0,099 \\
\hline 1 year & $0,207(0,081$ to 0,968$)$ & $0,324(0,111$ to 2,656$)$ & 0,051 \\
\hline 2 years & $0,141(0,092$ to 0,990$)$ & $0,458(0,071$ to 5,198$)$ & 0,005 \\
\hline \multicolumn{4}{|l|}{ Inclination in ${ }^{\circ}$} \\
\hline 1 week & $43,8(35,1$ to 60,0$)$ & $43,6(30,4$ to 60,3$)$ & 0,892 \\
\hline 3 months & $40,9(35,4$ to 61,2$)$ & $44,1(30,7$ to 61,3$)$ & 0,465 \\
\hline 1 year & $40,9(34,9$ to 59,3$)$ & $44,5(34,4$ to 60,4$)$ & 0,465 \\
\hline 2 years & $41,0(35,0$ to 61,0$)$ & $45,5(28,0$ to 68,0$)$ & 0,351 \\
\hline \multicolumn{4}{|l|}{ Arc of cover in $\mathrm{mm}$} \\
\hline 1 week & $14,6(7,7$ to 19,2$)$ & $13,4(5,4$ to 19,9$)$ & 0,372 \\
\hline 3 months & $15,5(7,0$ to 19,0$)$ & $13,9(5,2$ to 19,9$)$ & 0,244 \\
\hline 1 year & $15,2(8,2$ to 19,1$)$ & $13,1(5,7$ to 17,9$)$ & 0,223 \\
\hline 2 years & $16,0(7,6$ to 19,5$)$ & $13,8(6,0$ to 20,2$)$ & 0,281 \\
\hline
\end{tabular}

Mean values with their range are given for the inclination and the arc of cover.

$\mathrm{p}<0,005)$ 2-years after implantation (Figure 2a-c) and therefore, we confirm the first hypothesis. On the other hand, we refute the second study hypothesis as there was no significant correlation between the inclination of the acetabular component and the arc of cover with metal ion concentration neither in the resurfacing nor in the THA group (Table 3).

Several authors demonstrated that the concentrations of $\mathrm{Co}$ and $\mathrm{Cr}$ ions increase within the first 3 months to 2 years following metal-on-metal hip arthroplasty (so called run-in period) $[3,8,10-14,24,25]$. Imanishi et al. [8] related a not significant additional increasement of serum metal ion levels at one year follow-up, whilest Back et al.[10] and Daniel et al. [11,15] observed a decreasing trend within the first 6-years. Sauvè et al. [9] reported threefold and fivefold higher serum concentrations of $\mathrm{Co}$ and $\mathrm{Cr}$ following metal-on-metal hip arthroplasty compared to a control group during a 30-year follow-up. In 2010, deSouza et al. [2] related their 10year results following hip resurfacing with two key findings. They found a second increment of metal ion concentrations, five years following hip resurfacing and second they found no significant differences between women and men, which is contradict to other data in the literature. In the present study, we can not provide further information whether the metal ion levels will show a further increasement, whether they will reach a plateau phase or whether they will decrease. It seems that the patients are still in the prosthesis' run-in period and further follow-up has to be done to observe the development of metal ion concentrations.

Matthies et al. [1] recently showed that metal-on-metal hip resurfacing and modular total hip replacements have same wear rates and both types of devices are associated with increased blood levels of metal ions. Therefore, this group suggested that the problems related to high wear due to metal-on-metal articulation are likely to be similar in hip resurfacing as well as large-diameter hip arthroplasty [1]. Moroni et al. [4] also found no differences in mean $\mathrm{Co}, \mathrm{Cr}$ and Mo levels between patients with metalon-metal hip resurfacing and metal-on-metal THA at 2and 5-year follow-up. Furthermore, there were no 
Table 3 Results of correlation analysis

\begin{tabular}{|c|c|c|c|c|}
\hline \multicolumn{5}{|l|}{ ASR Resurfacing } \\
\hline Follow-up: 1 year & $\mathrm{Cr}$ & Co & Inclination & Arc of cover \\
\hline Co & Spearmen:, $855 ; p=0,007$ & & Spearmen: -,229; $p=0,586$ & Spearmen: ,229; $p=0,586$ \\
\hline $\mathrm{Cr}$ & & Spearmen:, $855 ; p=0,007$ & Spearmen: -,048; $p=0,911$ & Spearmen: ,048; $p=0,911$ \\
\hline Follow-up: 2 years & $\mathrm{Cr}$ & Co & Inclination & Arc of cover \\
\hline Co & Spearmen: $695 ; p=0,056$ & & Spearmen:,$- 530 ; p=0,177$ & Spearmen: ,539; $p=0,168$ \\
\hline $\mathrm{Cr}$ & & Spearmen: ,695; $p=0,056$ & Spearmen:,$- 778 ; p=0,023$ & Spearmen: $476 ; p=0,233$ \\
\hline \multicolumn{5}{|l|}{ ASR XL Head } \\
\hline Follow-up: 1 year & $\mathrm{Cr}$ & Co & Inclination & Arc of cover \\
\hline Co & Spearmen: ,819; $p<0,001$ & & Spearmen: ,192; $p=0,357$ & Spearmen: -,176; $p=0,389$ \\
\hline $\mathrm{Cr}$ & & Spearmen: ,819; $p<0,001$ & Spearmen:, $103 ; p=0,623$ & Spearmen:,$- 107 ; p=0,601$ \\
\hline Follow-up: 2 years & $\mathrm{Cr}$ & Co & Inclination & Arc of cover \\
\hline Co & Spearmen: ,805; $p<0,001$ & & Spearmen: $240 ; p=0,201$ & Spearmen: -,326; $p=0,073$ \\
\hline $\mathrm{Cr}$ & & Spearmen: ,805; $p<0,001$ & Spearmen:, $234 ; p=0,213$ & Spearmen: -,258; $p=0,161$ \\
\hline
\end{tabular}

Spearmen's correlation coefficient was calculated to determine correlations between metal ion concentration, inclination and arc of cover at, one and two years postoperatively.

significant differences within the implant groups at each time of determination. Only the ion concentrations were greater in patients with metal-on-metal devices compared to a control group $(\mathrm{p}<0,001)[4]$.

Otherwise, the current study and even the studies of Garbuz et al.[3] and Vendittoli et al. [28] showed that patients with metal-on-metal total hip arthroplasties had significantly higher concentrations of blood metal ions compared to patients undergoing hip resurfacing (Table 2).

The variability of the serum levels of metal ions is influenced by several factors such as different implant size, incorrect adjustment of the components, differences in manufacture and metallurgy as well as metal corrosion [4-8,16,17,21,22]. Shimmin et al. [21] reported the results of the Australian National Joint Registry showing an inverse relationship between the size of the femoral component and the risk of revision (component size $<44 \mathrm{~mm}$ have a fivefold higher risk of revision) following hip resurfacing. In the series of Langton et al. [7], 17 patients with the $\mathrm{ASR}^{\mathrm{TM}}$ device were revised due to adverse reaction to metal debris (ARMD). This group had significantly smaller components, higher acetabular component anteversion and higher whole blood concentrations of $\mathrm{Co}$ and $\mathrm{Cr}$ in contrast to asymptomatic patients (all $\mathrm{p}<0,001$ ).

In several other studies increased components' wear, edge loading and raised blood and/or serum ion levels were also correlated positively with the inclination of the acetabular component $[1,5-8,16,17,21,22]$. A comparative study of Langton et al. [17] showed increased metal ion levels in patients with resurfacing devices and an inclination greater than $45^{\circ}$, while Witzleb et al. [14] showed inverse results. Furthermore, a significant inverse relationship could be found between femoral size and Co and $\mathrm{Cr}$ concentrations [17]. Therefore, the authors stated that larger resurfacing implants seem to be more resistant to suboptimal position in terms of metal ion generation. This might be due to the thicker fluid film as well as the greater arc of cover [17]. On the other hand, the recent study showed no correlation between the metal ion levels in the serum, the inclination of the acetabular component, and the arc of cover (Table 3), possibly due to the small number of patients included in the study.

This study has some limitations: First, we only observed metal ion levels after a minimum follow-up of 2 years and therefore lack information of possible longterm effects and outcome. Second, the radiological evaluation of inclination and arc of cover lacks interand intraobserver coefficients. Third we observed a relatively small number of patients and the patients enrolled are split into two subpopulations. Fourth we did not perform an a priori power analysis but differences of outcome between the THA group compared to the resurfacing group were large enough yielding statistical significance and therefore adequate post hoc power.

\section{Conclusion}

Determining the serum concentrations of metal ions in patients following metal-on-metal hip resurfacing as well as metal-on-metal THA showed increments for Co and Cr. Furthermore, patients treated with large-diameter metal-on-metal total hip prostheses showed threefold and fourfold, respectively, higher levels for $\mathrm{Co}$ and $\mathrm{Cr}$ compared to patients with metal-on-metal resurfacing devices, 2-years following implantation. The effects of systemic metal ion exposure in patients with implants made of $\mathrm{Co}$ and $\mathrm{Cr}$ continue to be a matter of concern. 
In order to clarify the biologic effects of ion dissemination and to identify risks concerning long-term toxicity of metals, the exposure should be monitored carefully. Therefore, long-term studies have to be done to determine adverse effects of $\mathrm{Co}$ and $\mathrm{Cr}$ following metal-onmetal hip replacement.

\section{Competing interests}

The authors declare that they have no competing interests.

\section{Authors' contributions}

WME, JF, MP and MT participated in the design and the coordination of the study. WME, JF, PS and AL performed acquisition of the data. WME, JF, MP and PS drafted the manuscript. AL reviewed the manuscript critically. All authors read and approved the final manuscript.

\section{Acknowledgements}

We would like to thank Prof. Lorenz and his laboratory team for performing metal ion measurements in their laboratory.

Received: 3 August 2011 Accepted: 27 March 2012

Published: 11 April 2012

\section{References}

1. Matthies A, Underwood R, Cann P, Ilo K, Nawaz Z, Skinner J, Hart A : Retrieval analysis of 240 metal-on-metal hip components, comparing modular total hip replacement with hip resurfacing. J Bone Joint Surg Br 2010, 93:307-314.

2. deSouza RM, Parsons NR, Oni T, Dalton P, Costa M, Krikler S: Metal ion levels following resurfacing arthroplasty of the hip: serial results over a ten-year period. J Bone Joint Surg Br 2010, 92:1642-1647.

3. Garbuz DS, Tanzer M, Greidanus NV, Masri BA, Duncan CP: The John Charnley Award: Metal-on-metal hip resurfacing versus large-diameter head metal-on-metal total hip arthroplasty: a randomized clinical trial. Clin Orthop Relat Res 2010, 468:318-325.

4. Moroni A, Savarino L, Hoque M, Cadossi M, Baldini N: Do ion levels in hip resurfacing differ from metal-on-metal THA at midterm? Clin Orthop Relat Res 2010, 469:180-187.

5. De Haan R, Campbell PA, Su EP, De Smet KA: Revision of metal-on-metal resurfacing arthroplasty of the hip: the influence of malpositioning of the components. J Bone Joint Surg Br 2008, 90:1158-1163.

6. Langton DJ, Joyce TJ, Jameson SS, Lord J, Van Orsouw M, Holland JP, Nargol AV, De Smet KA: Adverse reaction to metal debris following hip resurfacing: the influence of component type, orientation and volumetric wear. J Bone Joint Surg Br 2011, 93:164-171.

7. Langton DJ, Jameson SS, Joyce TJ, Hallab NJ, Natu S, Nargol AV: Early failure of metal-on-metal bearings in hip resurfacing and large-diameter total hip replacement: A consequence of excess wear. J Bone Joint Surg Br 2010, 92:38-46.

8. Imanishi T, Hasegawa M, Sudo A: Serum metal ion levels after secondgeneration metal-on-metal total hip arthroplasty. Arch Orthop Trauma Surg 2010, 130:1447-1450.

9. Sauve P, Mountney J, Khan T, De Beer J, Higgins B, Grover M: Metal ion levels after metal-on-metal Ring total hip replacement: a 30-year followup study. J Bone Joint Surg Br 2007, 89:586-590.

10. Back DL, Young DA, Shimmin AJ: How do serum cobalt and chromium levels change after metal-on-metal hip resurfacing? Clin Orthop Relat Res 2005, 438:177-181.

11. Daniel J, Ziaee H, Pradhan C, Pynsent PB, McMinn DJ: Blood and urine metal ion levels in young and active patients after Birmingham hip resurfacing arthroplasty: four-year results of a prospective longitudinal study. J Bone Joint Surg Br 2007, 89:169-173.

12. Savarino L, Granchi D, Ciapetti G, Cenni E, Nardi Pantoli A, Rotini R, Veronesi CA, Baldini N, Giunti A: Ion release in patients with metal-on-metal hip bearings in total joint replacement: a comparison with metal-onpolyethylene bearings. J Biomed Mater Res 2002, 63:467-474.

13. Engh CA Jr: MacDonald SJ, Sritulanondha S, Thompson A, Naudie D, Engh CA: 2008 John Charnley award: metal ion levels after metal-onmetal total hip arthroplasty: a randomized trial. Clin Orthop Relat Res 2009, 467:101-111.
14. Witzleb WC, Ziegler J, Krummenauer F, Neumeister V, Guenther KP: Exposure to chromium, cobalt and molybdenum from metal-on-metal total hip replacement and hip resurfacing arthroplasty. Acta Orthop 2006, 77:697-705.

15. Daniel J, Ziaee H, Pradhan C, McMinn DJ: Six-year results of a prospective study of metal ion levels in young patients with metal-on-metal hip resurfacings. J Bone Joint Surg Br 2009, 91:176-179.

16. Langton DJ, Jameson SS, Joyce TJ, Webb J, Nargol AV: The effect of component size and orientation on the concentrations of metal ions after resurfacing arthroplasty of the hip. J Bone Joint Surg Br 2008, 90:1143-1151

17. Langton DJ, Sprowson AP, Joyce TJ, Reed M, Carluke I, Partington P, Nargol $\mathrm{AV}$ : Blood metal ion concentrations after hip resurfacing arthroplasty: a comparative study of articular surface replacement and Birmingham Hip Resurfacing arthroplasties. J Bone Joint Surg Br 2009, 91:1287-1295.

18. Pazzaglia UE, Apostoli P, Congiu T, Catalani S, Marchese M, Zarattini G: Cobalt, chromium and molybdenum ions kinetics in the human body: data gained from a total hip replacement with massive third body wear of the head and neuropathy by cobalt intoxication. Arch Orthop Trauma Surg 2011, 131(9):1299-308

19. Steens W, Loehr JF, von Foerster G, Katzer A: Chronic cobalt poisoning in endoprosthetic replacement. Orthopade 2006, 35:860-864

20. Oldenburg $M$, Wegner $R$, Baur $X$ : Severe cobalt intoxication due to prosthesis wear in repeated total hip arthroplasty. J Arthroplasty 2009, 24:825 e815-820.

21. Shimmin AJ, Walter WL, Esposito C: The influence of the size of the component on the outcome of resurfacing arthroplasty of the hip: a review of the literature. J Bone Joint Surg Br 2010, 92:469-476.

22. De Haan R, Pattyn C, Gill HS, Murray DW, Campbell PA, De Smet K Correlation between inclination of the acetabular component and metal ion levels in metal-on-metal hip resurfacing replacement. J Bone Joint Surg Br 2008, 90:1291-1297.

23. Hart AJ, Hester T, Sinclair K, Powell JJ, Goodship AE, Pele L, Fersht NL, Skinner J: The association between metal ions from hip resurfacing and reduced T-cell counts. J Bone Joint Surg Br 2006, 88:449-454.

24. Antoniou J, Zukor DJ, Mwale F, Minarik W, Petit A, Huk OL: Metal ion levels in the blood of patients after hip resurfacing: a comparison between twenty-eight and thirty-six-millimeter-head metal-on-metal prostheses. J Bone Joint Surg Am 2008, 90(Suppl 3):142-148.

25. Savarino L, Granchi D, Ciapetti G, Cenni E, Greco M, Rotini R, Veronesi CA, Baldini N, Giunti A: Ion release in stable hip arthroplasties using metalon-metal articulating surfaces: a comparison between short- and medium-term results. J Biomed Mater Res A 2003, 66:450-456.

26. Grubl A, Marker M, Brodner W, Giurea A, Heinze G, Meisinger V, Zehetgruber $\mathrm{H}$, Kotz R: Long-term follow-up of metal-on-metal total hip replacement. J Orthop Res 2007, 25:841-848.

27. De Smet K, De Haan R, Calistri A, Campbell PA, Ebramzadeh E, Pattyn C, Gill $\mathrm{HS}$ : Metal ion measurement as a diagnostic tool to identify problems with metal-on-metal hip resurfacing. J Bone Joint Surg Am 2008, 90(Suppl 4):202-208

28. Vendittoli PA, Amzica T, Roy AG, Lusignan D, Girard J, Lavigne M: Metal Ion release with large-diameter metal-on-metal hip arthroplasty. J Arthroplasty 2010, 26:282-288.

doi:10.1186/1471-2474-13-56

Cite this article as: Maurer-Ertl et al:: Metal ion levels in large-diameter total hip and resurfacing hip arthroplasty-Preliminary results of a prospective five year study after two years of follow-up. BMC Musculoskeletal Disorders 2012 13:56 